\title{
Special issue on PODC 2019
}

\author{
Hagit Attiya ${ }^{1}$
}

Accepted: 29 October 2021 / Published online: 12 November 2021

(c) The Author(s), under exclusive licence to Springer-Verlag GmbH Germany, part of Springer Nature 2021

This special issue of Distributed Computing is based on papers that originally appeared as extended abstracts in the Proceedings of the 38th Symposium on Principles of distributed computing (PODC 2019), held in Toronto, Ontario, Canada.

The papers for the Special Issue were chosen by the Program Committee from the regular papers presented at the symposium, based on their quality and representation of the spectrum of topics encompassed by the Symposium. In addition to being reviewed, in preliminary form, by the Program
Committee, the full papers submitted for the Special Issue were refereed according to the standard practices of Distributed Computing. We thank the program committee, the handling editors, the referees and the authors of these papers.

Publisher's Note Springer Nature remains neutral with regard to jurisdictional claims in published maps and institutional affiliations.

Hagit Attiya

hagit@cs.technion.ac.il

1 Technion, Haifa, Israel 